\title{
Paste quality control benchmarks
}

\author{
David Stone \\ President, MineFill Services, Inc., Bothell, USA
}

SUMMARY: Routine sampling and testing of paste mixes with uniaxial compression test cylinders is an accepted industry practice for routine monitoring of paste quality and strengths. However, unlike the concrete industry, there is no industry accepted quality control standard for assessing the results, or for determining what actions, if any, need to be taken. This paper sets out the groundwork for an industry standard for interpretation of routine quality control testing of paste mixes. The paper will examine the variability of several key benchmarks based on mine site quality control databases, and provides a draft assessment criteria.

Keywords: paste, quality, sampling, strength

\section{INTRODUCTION}

In the absence of an industry standard, most mines rely on concrete standards to design and interpret their backfill quality control (QC) programs. In the USA these standards are developed and published by organizations such as ASTM (American Society of Testing and Materials) and ACI (American Concrete Institute). However, the application of these standards to cemented backfills can be very difficult owing to the high degree of variability in backfill mixes, and the resulting variability in QC test results.

To illustrate, concrete industry standards denote an acceptable (passing) test result occurs when the average of the duplicate test cylinders exceeds the target strength, and no single test result deviates from the target strength by more than 10 percent (ACI 214R). Remedial measures must be taken if three consecutive tests fail. With mine backfills, it is safe to say that these criteria are rarely achievable.

A further, more dramatic, example is the coefficient of variation for concrete QC cylinders. According to ACI 214R, the coefficient of variation (CV) can range from 3 percent (excellent rating) to 6 percent (poor rating). Applying this analysis method to several paste QC databases from operating mines, the author notes that a coefficient of variation in the order of 20 to 30 percent is more typical.

Clearly there is a need to develop a better industry standard for assessing paste backfill quality to assist mine operators with interpreting test results and developing action plans in the event of undesired outcomes.

\section{PASTE FILLS VERSUS CEMENTED ROCKFILLS}

Routine quality control sampling is commonplace for both cemented rockfills and cemented paste fills but there are some differences. First, cemented rockfills are highly variable owing to the aggregate gradings which can vary dramatically over even short periods of time (see Stone 
(2007, 2019)). Cemented paste fills, on the other hand, tend to be more consistent because the mix ingredients are better controlled. As such there tends to be far less variability in paste mix quality control test data, compared to cemented rockfills.

Another consideration is the number of mix recipes in use, and hence the strength benchmarks for interpreting the QC test results. In cemented rockfills a typical mix plant might be programmed with 4 or 5 recipes. Entire stopes are filled with a single recipe. With paste fills the mix recipes can vary on a daily basis, and a single stope may utilize several different recipes (e.g. plug pours versus bulk pours). This complicates the strength assessment of the QC test data as the target strengths are constantly changing.

In concrete all of the QC strengths are benchmarked to a 28 day cure. The same is largely true for cemented rockfills. Even though the stope turnaround may be as few as 7 days, ultimately the QC data, and the backfill specifications, are assessed on the basis of 28 day strengths.

This is not necessarily true for paste fills where 3 day, 7 day and 14 day strengths may be the only strength benchmarks that are set. Paste generally does not follow the traditional 7 , 14 , and 28 day curing curve seen in concrete hence paste strengths may not benchmarked to a 28 day cure. An example is the paste plug pour which is typically benchmarked to a 24,48 or 72 hour cure. In fact, the rapid strength gains in paste can further complicate QC testing as the samples must be broken on a very regular schedule to avoid de-rating the results.

\section{FACTORS THAT IMPACT PASTE UCS}

Not all pastes behave the same and hence the rheology and strength of paste mixes can be highly variable. Table 1 shows a range of average paste strengths from QC test cylinders at 6 operating mines. The strength ranges across these six projects can be ten-fold or more. This table is based on several thousand QC strength tests.

The main culprit for the variability in the strength of paste mixes is typically a combination of the paste rheology (yield stresses in the paste mix) and the tailings mineralogy. Some of the factors that can impact paste strengths in the laboratory are described in more detail in the following sections.

Table 1. Average paste strengths from selected mine databases.

\begin{tabular}{llllll}
\hline & Binder Type $^{1}$ & $2.5 \%$ Binder & $3.0 \%$ Binder & $5.0 \%$ Binder & $6.0 \%$ Binder \\
\hline Mine A - 7d & OPC & 0.72 & 0.54 & 1.21 & \\
Mine A - 28d & OPC & 1.50 & 1.39 & 2.26 & \\
Mine B - 7d & OPC/FA & 0.06 & 0.06 & 0.10 & 0.16 \\
Mine B - 28d & OPC/FA & 0.18 & & & 0.33 \\
Mine C - 7d & OPC & & 0.21 & 0.25 & 0.26 \\
Mine C - 28d & OPC & & 0.29 & 0.45 & 0.51 \\
Mine C - 7d & MINCEM & 0.22 & 0.24 & 0.52 & \\
Mine C - 28d & MINCEM & 0.36 & 0.41 & 0.88 & \\
Mine D - 7d & MINCEM & 0.45 & 0.40 & 0.60 & \\
Mine D - 28d & MINCEM & 0.48 & 0.65 & 0.80 & \\
Mine E - 7d & OPC & & & 0.21 & \\
Mine E - 28d & OPC & & 0.41 & 0.27 & \\
Mine E - 7d & BFS & & 0.47 & 0.35 & \\
Mine E - 28d & BFS & & 0.06 & & \\
Mine F - 7d & OPC/FA & & 0.10 & & \\
Mine F - 28d & OPC/FA & & &
\end{tabular}

Note 1: OPC = Ordinary Portland, FA = Fly Ash, BFS = blast furnace slag. MinCem = OPC/BFS blend. Source: MineFill Services client databases 


\subsection{Factors that impact paste UCS - mix water quality}

The chemistry of the trim water or mix water used to prepare paste can have a direct impact on the paste quality. The prime culprit typically is dissolved sulphates $\left(\mathrm{SO}_{4}\right)$ from the oxidation of sulphide minerals. During metallurgical processing, ores with high sulphide contents, such as pyrite, can result in process water with very high sulphate values.

In the authors experience, the threshold for paste degradation is around 2,500 $\mathrm{ppm} \mathrm{SO}_{4}$ which is similar to the threshold for concrete. Sulphate degradation of cement is a welldocumented phenomenon, and in paste backfills as it can lead to a rapid and significant loss of paste strengths in the laboratory after 28 days (see Pierce et al (1998), Benzaazoua et al. (2002)). There is however, some debate as to whether this is a laboratory induced issue due to oxidation during laboratory curing, or whether this extends to curing of paste confined in a stope. However, projects with very high sulphides will typically extend the QC testing to 56 or even 90 days to check for sulphate reactions.

Hyper-salinity in groundwater used for paste mixing is an issue for some mines. Hypersalinity also occurs in soda ash and trona paste mixes due to salts dissolved in the process. Hyper-salinity has two significant impacts on paste: one is on the rheology, and the other is on the cement hydration and ultimately the strength of the paste.

Typically, the higher the salt content, the lower the yield stress. Tests by Jiang and Fall (2017) show a 40 percent reduction in yield stress for paste mixes with $100,000 \mathrm{mg} / \mathrm{L}$ of salt compared to mixes with zero salinity. It is important to understand that dissolved salts also affect the density of the carrier water that suspends the solids in the paste. At the Frogs Leg mine in Australia, for example, the paste carrier water was found to have a density of $1.15 \mathrm{t} /$ $\mathrm{m}^{3}$ due to $210,000 \mathrm{mg} / \mathrm{L}$ of dissolved salts (Mgumbwa and Nester (2014)). Hence interpreting rheology results on the basis of solids content alone can be misleading. Yield stresses should be correlated with the total density of the slurry and not just the solids content.

The strength of paste mixes that use hypersaline mix waters decreases as the salt content increases, however these mixes do show increasing strengths with increased curing. Tests by Jiang and Fall (2017) show an 85 percent reduction in 28 day paste strengths for paste mixes with $100,000 \mathrm{mg} / \mathrm{L}$ of salt compared to mixes with zero salinity. The loss in strength is attributed to the replacement of $\mathrm{Ca}^{2+}$ with $\mathrm{Na}^{+}$in the C-S-H cement hydration products.

\subsection{Factors that impact paste UCS - tailings mineralogy}

The single biggest influence on the strength of paste is the mineralogy of the tailings. This is particularly true for tailings with a very high specific gravity of solids such as sulphide rich tailings. Pyrite has a specific gravity of about 5.0 and pyrrhotite has a specific gravity of 4.5 . Paste mixes with significant sulphide contents can have densities of 2.5 tonnes per cubic meter or more.

The significance of the specific gravity of the solids of the tailings is related to the binder additions which are always measured as a percentage of the weight of the dry solids. The result is that paste mixes with high density solids will contain a higher binder content on a volumetric basis. This then leads to higher strengths since the binder hydration reactions are based on volumes not solids content (see Fall et al. (2007)).

Paste batched with high specific gravity tailings are also susceptible to a rapid settling of solids in QC test cylinders. This creates a significant water bleed which lowers the water to cement ratio in the cured cylinders, which increases the laboratory measured density of the paste.

The presence of micas in tailings can be problematic because these minerals are hydrophilic and can absorb water into their crystal matrix. This can result in a gradual reduction of the free water in the paste, resulting in significant changes in the yield stress of the paste mix. These paste mixes are generally thixotropic, and care must be taken to avoid time dependant changes in the yield stress.

The processing of rare earths can result in oxidation products in the tailings that can be especially troublesome. The calcining of rare earths can produce calcium oxide $\mathrm{CaO}$ or quicklime which is unstable in the presence of water. In a recent laboratory program the quicklime was seen 
to undergo a rapid and violent exothermic reaction which not only boiled the water in the paste, but was also accompanied by a 200 percent volumetric expansion.

\subsection{Factors that impact paste UCS - sampling location}

Routine sampling of paste for QC testing is commonly done at mixer discharge at the paste plant. Since the majority of paste plants are located at the surface, the samples are generally transferred to a temperature-controlled surface laboratory. Some paste plants are located underground, in which case the samples are cured underground, or else transferred to the surface laboratory.

Less commonly, the paste sampling can be done at the discharge into the stope. Typically these samples would be cured and tested at an underground paste laboratory.

Testing has shown that the location for collection of the paste QC samples has little to no impact on the strengths recorded in QC testing. Hughes et al (2013) reports on an investigation at the Stillwater mine in Montana to address concerns about variances in paste strengths due to the long reticulation distances. Stillwater collected 86 comparative samples at both the paste plant and underground at the stope. The testing showed no statistically significant difference in the strength of QC cylinders collected at the surface paste plant compared to cylinders collected underground at the stope discharge.

Donovan et al. (2007) carried out a similar exercise at the David Bell mine in Canada, and likewise their results did not show any particular bias to one method or the other.

In cemented rockfills the human factor can play a significant role in the final strength of QC test cylinders (Stone $(2007,2019))$. The variability introduced by different operators can range from samples that are over-tamped and on the verge of being concrete, to cylinders with excessive voids, poor end preparation, or in some extreme cases, cylinders that are not even full. Generally, the majority of reject cylinders will be consistently produced by one operator. Fortunately, this is not an issue in paste sampling because there is no sample preparation other than ensuring the cylinders are full and capped properly to prevent moisture loss.

\subsection{Factors that impact paste UCS - sample size effects}

De-rating of sample strengths due to the sample size is common with both concrete and CRF, but does not appear to be needed for paste fills. Hughes et al (2013) reports that no conclusive trend could be found between sample size and UCS. The authors own project databases likewise show that the UCS of QC test cylinders is not sensitive to the cylinder size. NIOSH did find that samples less than $38 \mathrm{~mm}$ in diameter can over-estimate the paste strength. This was attributed to a possible accelerated curing effect in small diameter samples which have a higher surface area to volume ratio.

Scaling down the sample size has a number of positive benefits. The most notable is the size and volume of the curing cabinet needed to store samples. A typical paste operation would collect 4 to 6 samples per shift (for 3, 7, and 28 day breaks) resulting in the need to store upwards of 75 samples each weighing approximately $11 \mathrm{~kg}$ each. Hence most paste operations have scaled their QC cylinders down to a much more manageable $50 \mathrm{x} 100 \mathrm{~mm}$ or 100 x $200 \mathrm{~mm}$ samples. The smaller sample volume takes up less space, and is far easier and safer to handle than full size concrete samples.

\subsection{Factors that impact paste UCS - curing conditions}

The curing conditions can have a significant impact on the QC test results. The ASTM C31 standard calls for an initial 48 -hour cure at 16 to $27^{\circ} \mathrm{C}$ in an environment preventing moisture loss. After the initial cure, the samples are to be stripped from the molds and cured in a 100 percent humidity environment at $23{ }^{\circ} \mathrm{C}$ (or stored in a water tank).

Most paste sampling is carried out remote from the QC laboratory hence the samples have to be moved. Ideally these samples would follow an initial cure period in conformance with the 
ASTM guidelines. Typically, the curing of paste samples is done in a humidity cabinet, a humid controlled room, or even sealed plastic bags with a wet cloth.

There are two issues unique to the curing of paste samples. The first is the result of stripping the samples from the molds after the initial curing period. In pastes that contain appreciable sulphides, stripping the samples exposes the sulphides to air, which in turn triggers the production of sulphates and low $\mathrm{pH}$. Because these reactions are exothermic, the heat of oxidation results in accelerated hydration of the cement. This can lead to some very interesting high early strengths. In one example the mine QC testing produced 7 day strengths of over $1 \mathrm{MPa}$, and 28 day strengths of over $2 \mathrm{MPa}$, with just 3 percent binder. This phenomenon is particularly troublesome in samples with high pyrrhotite contents. Unfortunately, these high early strengths are typically not sustained in the stope environment hence in-stope strengths can be found to be much lower than the laboratory strengths. An interesting comparison between samples that were sealed for 112 days versus samples stripped after 28 days, but cured for 112 days, can be found in Pierce et al. (1998).

The second issue is the result of allowing the samples to lose moisture due to improper storage. This can be witnessed in hot jurisdictions where the paste laboratory is housed in a standard shipping container without a proper temperature or humidity controls. The result, again, is abnormally high strengths as a result of a loss of the water needed to hydrate the cement, or accelerated curing from the excessive heat.

\section{INTERPRETATION OF QC TEST RESULTS}

The majority of mines enter the QC test data into an EXCEL spreadsheet and then produce a basic quality control chart such as an x-y plot of UCS versus time (Figure 1). When the data falls outside of the desired limits it should serve as a trigger that some form of action is needed. The reality is that most mines do not understand the trigger mechanisms coming from this type of plot because so many QC cylinders fail.

The preferred method for periodic review of backfill QC test data is the cumulative sums (CUSUMS) chart in accordance with ACI 214R-02. The cumulative sums chart is a cumulative summation of the deviation from an average for a series of tests over time. The CUSUMS chart

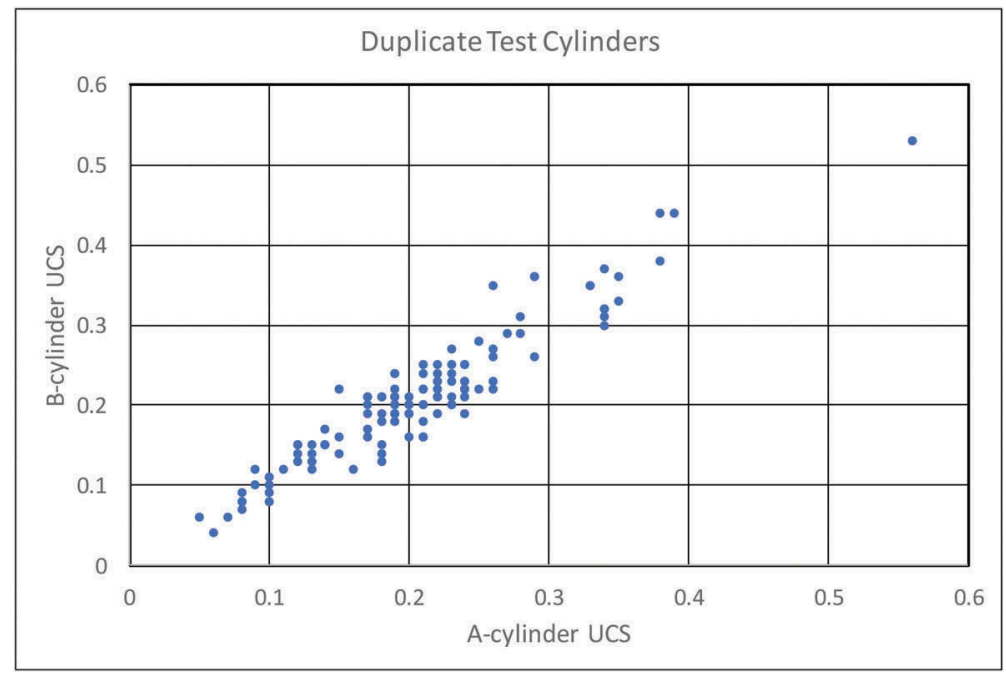

Figure 1. Variability in duplicate test cylinders.

Source: MineFill Services client databases 
provides a method for detecting relatively small changes in the average strength of QC cylinders. It can help to identify when the change occurred and the approximate magnitude of the shift in strengths. As noted in ACI-214R, the charts provide greater sensitivity in detecting small, systemic changes in the average strength as compared to the basic quality control chart. A good example of the power of a CUSUMS chart is given in Stone (2007).

\section{VARIABILITY IN SAMPLE DUPLICATES}

A well run backfill QC program includes the collection of duplicate QC test cylinders, or in some cases, triplicates. It has been noted that concrete standards require the average of both cylinders to exceed the target strength, and no cylinder can deviate from the target strength by more than 10 percent.

Very few mines setup their databases to allow a direct comparison of the results from duplicate test cylinders hence this is a very difficult benchmark to track. However, a review of client databases showed deviations between duplicate cylinders (A versus B) that ranged from 6 percent to 46 percent. A plot of typical A versus B cylinder results is shown in Figure 1. Typically, the correlation coefficient comparing datasets for duplicate samples is very high (>95 percent) indicating a very strong correlation.

\section{COEFFICIENT OF VARIATION}

Under normal conditions the QC test results are expected to fit into a normal frequency distribution curve clustered around the mean. The dispersion of the test data is typically measured by calculating the standard deviation. However, in the case of backfill, a better measure of the variability of the test data is the coefficient of variation $(\mathrm{CV})$ or relative standard deviation. The $\mathrm{CV}$ tends to be less affected by the variation in mean strength values and hence provides a more useful measure of the variability over a wide range of strengths.

As noted in the introduction, $\mathrm{CV}$ values for concrete can range upwards of 6 percent which is notably different than mine backfills. Reviewing client QC databases for a number of paste projects, CV values were found to range from a low of 15 percent, to a high of 60 percent. Most of the data (see Table 2) is clustered around an average CV value of about 35 percent.

Table 2 does give some insight into the factors that affect the CV value. The CV does vary according to the curing period (e.g. one set of samples does not exhibit the same $\mathrm{CV}$ at various curing periods), however no consistent trends are evident. There does appear to be a trend related to the type of binder. Much of the data in the table suggests that non-Portland Cement binders result in higher CV values: in other words Portland Cement is far more predictable and consistent as a binder.

\section{LABORATORY STRENGTHS VERSUS IN-STOPE STRENGTHS}

One of the critical benchmarks for paste backfills is the relationship between the strengths measured in laboratory QC samples compared to in-stope paste strengths. In cemented rockfills it has been established that in-stope strengths are typically lower than the laboratory strengths, in-part because of a strength de-rating due to sample size (see Stone et al (2019)). It has been shown herein de-rating of strengths does not apply to paste fills, hence it should not be a surprise that laboratory QC strength values are typically indicative of short term (6 month) in-stope paste strengths.

A number of investigations have shown that the strength of cured paste is a function of the confining pressure, hence paste strengths generally increase with depth in a stope. There is also a lot of evidence that paste continues to gain considerable strength after the standard 28 day cure. Bloss and Rankine (2005), for example, present the results of laboratory testing of Cannington paste samples subjected to long term curing. Their results showed the paste 
Table 2. Coefficient of variation from selected mine databases.

\begin{tabular}{llllll}
\hline DataBASE & Binder Type $^{1}$ & $2.5 \%$ Binder & $3.0 \%$ Binder & $5.0 \%$ Binder & $6.0 \%$ Binder \\
\hline Mine A - 7d & OPC & $36.5 \%$ & $35.8 \%$ & $30.6 \%$ & \\
Mine A - 28d & OPC & $24.8 \%$ & $21.0 \%$ & $27.6 \%$ & \\
Mine B - 7d & OPC/FA & & $33.3 \%$ & & $31.9 \%$ \\
Mine B - 28d & OPC/FA & & & & $40.9 \%$ \\
Mine C - 7d & OPC & & $24.2 \%$ & $42.0 \%$ & $41.5 \%$ \\
Mine C - 28d & OPC & & $31.9 \%$ & $46.5 \%$ & $30.2 \%$ \\
Mine C - 7d & MINCEM & $51.9 \%$ & $53.3 \%$ & $48.6 \%$ & \\
Mine C - 28d & MINCEM & $58.9 \%$ & $45.0 \%$ & $34.4 \%$ & $32.4 \%$ \\
Mine D - 7d & MINCEM & $35.4 \%$ & $31.5 \%$ & $31.0 \%$ & $22.5 \%$ \\
Mine D - 28d & MINCEM & $27.5 \%$ & $22.8 \%$ & $58.3 \%$ & \\
Mine E - 7d & OPC & & & $45.8 \%$ & \\
Mine E - 28d & OPC & & $35.9 \%$ & $43.8 \%$ & \\
Mine E - 7d & BFS & $51.7 \%$ & $17.1 \%$ & \\
Mine E - 28d & BFS & & $21.2 \%$ & & \\
Mine F - 7d & OPC/FA & & $17.4 \%$ & & \\
Mine F - 28d & OPC/FA & &
\end{tabular}

Note 1: OPC $=$ Ordinary Portland, FA $=$ Fly Ash, BFS $=$ blast furnace slag. MinCem $=$ OPC $/$ BFS blend. Source: MineFill Services client databases

undergoes two curing cycles: an initial 28 day cure, followed by a second cycle after about 6 months for low binder content samples, or 4 months for high binder content samples. The second curing cycle was observed to double or even triple the 28 day strengths over a period of 12 months.

The Cannington observations are supported by a number of studies with in-stope block sampling and coring of paste. Typically these samples yield paste strengths far in excess of the 28 day strengths measured in the QC samples. Recent coring of paste at an operation in the Red Lake area of Canada, for example, showed in-stope paste strengths averaging 3.2 $\mathrm{MPa}$ after 78 days of curing, compared to laboratory QC cylinders which averaged 1.05 MPa after 56 days. This is strength gain of over 3 -fold.

The question of paste degradation due to the oxidation of sulphides was recently addressed at a mine in Peru. In this case, Standard Penetration Testing (SPT) with a cone was conducted in paste filled stopes up to $30 \mathrm{~m}$ high, for paste with ages ranging from 60 days to 300 days. As expected, the SPT results showed increasing strengths with curing time, and also with depth in the stope. The laboratory QC test results at various curing times were then compared with the results of intact block samples collected in test pits and from subsequent fill exposures. In most instances the block sampling results were significantly lower than the laboratory QC test values, but in some stopes the results were very similar. This is not considered definitive proof of degradation of the paste as intact block sampling of paste has been shown to be very difficult and the results are typically disappointing.

\section{EVALUATING QC DATA ON A DAILY BASIS}

The case has already been made that backfill quality control test results typically exhibit considerable scatter, and also exhibit a significant number of "failures" (cylinders with UCS values under the target strength). This is normal in a mine environment. Given that test failures are accepted, guidelines are needed to determine if the fill being placed is acceptable. The ultimate goal is to prevent the placement of large quantities of poor quality fill.

QC test data can be separated into two groups. The first is daily samples collected during operation of the paste plant. These would consist of duplicate sets of some combination of 3 , 7, 14 and 28 day test cylinders. During continuous operation of the paste plant the QC 
laboratory would be receiving and breaking these cylinders on a daily basis in accordance with the curing schedule.

The second grouping of these same samples is assigning the results to an individual stope. This topic is discussed later in the paper.

So what are the consequences of failure of both of the duplicate sample cylinders tested on the same day? In concrete this would be considered a failure. However, after reviewing several mine QC databases it would appear that this occurs in about 10 percent of the cylinders.

What about the failure of both samples over 2 consecutive days? However, again this seems to be a fairly common event occurring in about 5 percent of the cylinders. The same is true for 3 consecutive days of QC testing.

However, it does appear that it is rare for QC testing to result in four consecutive days of failures in duplicate cylinders. Hence it would appear that any issues in the backfill plant that result in low paste strengths typically persist for about 3 days. This is likely a function of the volume of individual stope pours - in other words the issues are not realized or corrected until the end of the pour. It should be clarified that the sample failures we refer to herein relate to consecutive samples for the same cure period (e.g. consecutive 3 day or 7 samples) and not to the testing of 3 day samples, then 7 day samples and so on from the same paste batch.

\section{EVALUATION QC DATA ON A PER STOPE BASIS}

ACI and ASTM standards recommend a minimum of 15 duplicate samples in order to produce an adequate population of samples for statistical accuracy. For a typical $1,000 \mathrm{~m}^{3}$ pour at $60 \mathrm{~m}^{3} / \mathrm{h}$ this equates to one sample set every hour. For pours over $10,000 \mathrm{~m}^{3}$ this equates to about one sample set per shift.

The key question in evaluating the QC strength data on a per stope basis is how many samples are allowed to fail before the stability of the backfill mass becomes a concern. The best answer to this question can be found in Helinski et al (2017) which presents the results of a reliability analysis conducted with FLAC3D on a hypothetical $50 \mathrm{~m}$ tall x $25 \mathrm{~m}$ wide vertical exposure of backfill. The model randomly assigned strengths to $2 \mathrm{~m}$ cubed blocks based on a Gaussian distribution over a range of standard deviations. The results showed that the fill mass would remain stable provided the $\mathrm{CV}$ value was less than 60 percent, and that 66 percent of the fill mass exceeded the target strength required for stability. As the CV is increased the volume of paste that exceeds the target strength also needs to increase.

Based on the Helinski models, the author recommends the following guidelines:

- the acceptable failure rate in laboratory samples for a given stope should be about 1 in $4 \%$ or $25 \%$,

- the mean laboratory value for all QC testing in a given stope should be above the target strength. This implies the in-stope "mass" strength will be better than the target strength.

A back analysis of actual stope failures would help to refine this analysis. However, the long-term curing trend of paste makes these guidelines conservative for paste exposures that exceed a 28 day cure.

\section{CONCLUSIONS}

The variability of uniaxial compressive strengths in paste QC test cylinders is not unexpected given the broad range of factors that can have an influence. These factors include the tailings chemistry, the curing conditions, and the type of binder, just to name a few.

Applying concrete standards to the evaluation of backfill quality control samples has been shown to be problematic. Hence the author has developed the following assessment criteria based on a review of QC data from operating mines (Table 3). 
Table 3. Recommended assessment criteria for paste QC cylinders.

\begin{tabular}{ll}
\hline Benchmark & Acceptance Criteria \\
\hline UCS results & CV $<30 \%$ \\
A versus B Cylinders & Coefficent Correllation $>95 \%$ \\
& $<10 \%$ difference in UCS \\
Daily UCS & Duplicate cylinders on consecutive days fail for $<4$ days in a row. \\
Per Stope UCS & Minimum 15 cylinders \\
& $75 \%$ of cylinders exceed target UCS \\
& Mean UCS of all cylinders $>$ target UCS \\
\hline
\end{tabular}

\section{ACKNOWLEDGMENTS}

The author acknowledges the many contributions of client databases for analysis and review in the preparation of this paper. This is a work in progress and the author hopes to update the acceptance criteria as more data becomes available.

\section{BIBLIOGRAPHY}

Benzaazoua, M., Belem, T, Bussière, B. 2002. Chemical factors that influence the performance of mine sulphidic paste backfill. [In] Cement and Concrete Research, Vol 32, Pergamon, pp 1133-114.

Bloss, M.L., Rankine, R. 2005. Paste fill operations and research at Cannington Mine. [In] Ninth Underground Operators Conference. Perth, 7-9 March 2005. AusIMM Melbourne. pp 141-150.

Donovan, J., Dawson, J., Bawden, W.F. 2007. David Bell mine underhand cut and fill sill matt test. [In] Proceedings of the Ninth International Symposium on Mining with Backfill: Minefill 2007, Montreal, Quebec, Canada, 29 April - 3 May 2007, eds. F. Hassani et al.

Fall, M., Benzaazoua, M., Ouellet, S. 2004. Effect of tailings properties on paste backfill performance. [In] Proceedings 8th International Symposia on Mining with Backfill: Minefill 2004. Beijing, China, 2004. pp. 193-202.

Jiang, H., Fall, M. 2017. Yield stress and strength of saline cemented tailings in sub-zero environments: Portland cement paste backfill. [in] International Journal of Mineral Processing. Vol. 60, Elsevier, pp 68-75.

Helinski, M, Merrikin, D. 2017. Reliability analysis of mine backfill exposures. [In] Proceedings of the Twelfth International Symposia on Mine Backfill: Minefill 2017. Denver, 19-22 February 2017. Society for Mining, Metallurgy and Exploration, pp 281-294.

Hughes, P.B., Pakalnis, R., Deen, J., Ferster, M. 2013. Cemented paste backfill at the Stillwater Mine. [In] Proceedings of the $47^{\text {th }}$ US Rock Mechanics Symposia. San Francisco, 23-26 June 2013. ARMA pp $1230-1236$.

Mgumbwa, J., Nester, T. 2014. Paste improvements at La Mancha's Frog Leg underground mine. [In] Proceedings of the Eleventh International Symposia on Mine Backfill: Minefill 2014. Perth, Australian Centre for Geomechanics, pp 281-294.

Pierce, M.E., Bawden, W.F., Paynter, J.T. 1998. Laboratory testing and stability analysis of paste backfill at the Golden Giant Mine. [In] Proceedings of the Sixth International Symposia on Mine Backfill: Minefill 1998. Brisbane, 14-16 April 1998, Australian Centre for Geomechanics, pp 159-165.

Stone, D.M.R. 1993. The optimization of mix design for cemented rockfill. [In] Proceedings of the Fifth International Symposia on Mining with Backfill: Minefill 93. The South African Institute of Mining and Metallurgy Symposium Series S13, Johannesburg, ed. H.W. Glen, 249-253.

Stone, D.M.R. 2007. Factors that affect cemented rockfill quality in Nevada mines. [In] Proceedings of the Ninth International Symposium on Mining with Backfill: Minefill 2007, Montreal, Quebec, Canada, 29 April - 3 May 2007, eds. F. Hassani et al.

Stone, D.M.R., Pakalnis, R., Seymour, B. 2019. Interpreting backfill QA/QC test data - Do we need an industry standard?. [In] Proceedings SME Annual Meeting. Denver 24-27 February 2019. SME Pre-Print $19-043$. 